\title{
Cuidado de enfermagem à pessoa com comportamento suicida na Atenção Primária
}

\section{à Saúde}

Nursing care to suicidal behavior person at Primary Health Care

Cuidado de enfermeria a personas com comportamiento suicida en la Atención Primária a la Salud

Recebido: 30/08/2021 | Revisado: 04/09/2021 | Aceito: 06/09/2021 | Publicado: 07/09/2021

Karin Gabriele Bender

ORCID: https://orcid.org/0000-0003-2070-7145 Universidade de Santa Cruz do Sul, Brasil E-mail: kaaarinbender@hotmail.com

Fernanda de Conto

ORCID: https://orcid.org/0000-0001-5622-5303 Secretaria Municipal de Saúde de Florianópolis, Brasil E-mail: fernandaconto@hotmail.com

Jeferson Rodrigues

ORCID: https://orcid.org/0000-0002-8612-9088 Universidade Federal de Santa Catarina, Brasil E-mail: jef_rod@hotmail.com

\begin{abstract}
Resumo
Objetivo: Compreender o cuidado prestado por enfermeiros da atenção primária à saúde de Florianópolis à pessoa com comportamento suicida. Método: Pesquisa de abordagem qualitativa, do tipo descritiva realizada com 10 enfermeiros através de entrevista semiestruturada. Dados analisados por Análise de Conteúdo modalidade temática. Resultados: Emergiram duas categorias temáticas: O contexto do cuidado à pessoa com comportamento suicida na Atenção Primária à Saúde e Limites, desafios e possibilidades ao atendimento da pessoa com comportamento suicida. Conclusão: $\mathrm{O}$ estudo demonstrou que os enfermeiros estão ininterruptamente fazendo parte deste cuidado que se desenvolve no âmbito multidisciplinar e interdisciplinar, identificando a pessoa em risco de suicídio, realizando escuta para minimizar sofrimento e mobilizando a rede familiar e social. Os limites percebidos que se configuram como possibilidades de melhoria estão relacionados à formação e educação em serviço dos profissionais e à necessidade de estruturação da rede para o atendimento a pessoa com comportamento suicida.
\end{abstract}

Palavras-chave: Cuidados de enfermagem; Enfermagem; Atenção Primaria à Saúde; Suicídio; Ideação suicida.

\begin{abstract}
Objetive: to understand the care provided by nurses from florianópolis primary health care to suicidal behavior person. method: qualitative approach research, descriptive type with ten nurses using semi-structured interview. data was analyzed with content analysis in thematic modality. results: two categories emerged: the care context to suicidal behavior person at primary health care and limits, challenges and possibilities to suicidal behavior person assistance. conclusion: the study showed that nurses are uninterruptedly taking part on this care that happens in a multidisciplinary and interdisciplinary scope, by indentifying person in suicide risk, listening to minimize the suffering and mobilizing family and social support networks. the perceived limits that emerge as possibilities are related to professional qualification and in-service education and the necessity of structuring the health network to care person in suicidal behavior.
\end{abstract}

Keywords: Nursing care; Nursing; Primary Health Care; Suicide; Suicidal ideation.

\section{Resumen}

Objetivo: Comprender el cuidado prestado por enfermeros de la atención primária a la salud de Florianópolis a las personas con comportamientos suicidas. Método: Búsqueda del enfoque cualitativo, del tipo descriptivo realizada con diez enfermeiros a través de una entrevista semi estructurada. Datos analizados por Análisis de Contenido em Modalidad Temática. Resultados: Han surgido dos categorias temáticas: El contexto del cuidado a las personas con comportamiento suicida en la atención primária a la salud y, Límites, desafios y posibilidades al atendimiento de la persona con comportamiento suicida. Conclusión: El estudio ha demostrado que los enfermeros estan ininterruptamente haciendo parte del cuidado que se desarrolla en el ambito multidisciplinar e interdisciplinar, identificando a las personas en riesgo de suicídio, realizando escucha para minimizar el sufrimiento y mobilizando su red de apoyo familiar y social. Los limites encontrados que se configuran como posibilidades de mejora están relacionados a la instrucción, formación y educación en servicio de los profesionales y a la necesidad de estructurar la red para el atendimento a la persona con comportamientos suicidas.

Palabras clave: Atención de enfermería; Enfermería; Atención Primaria de Salud; Suicidio; Ideación suicida. 


\section{Introdução}

O tema do suicídio é complexo e multifacetado, pois sua leitura integra reflexões históricas e posições teóricometodológicas que envolvem diversas variáveis sobre o tema. No campo da saúde, o suicídio tem se configurado como um problema de saúde pública. O Brasil é o oitavo país em número de suicídios no mundo (Almeida et al, 2015). No mundo, a cada 40 segundos uma pessoa comete suicídio e, para cada suicídio, 20 ou mais pessoas realizaram tentativas, ou seja, a cada três segundos uma pessoa atenta contra a própria vida (OMS, 2000). A magnitude do suicídio levou os Estados membros da Organização Mundial de Saúde, o qual o Brasil está incluído, a estabelecerem no Plano de Ação de Saúde Mental a meta global de reduzir em 10\% a mortalidade por suicídio até 2020 (OMS, 2018).

O comportamento suicida é contextualizado como um processo complexo, que pode variar desde a ideia de retirar a própria vida, comunicada ou não por meios verbais e não verbais, compreendendo desde o pensamento, a ideação, o planejamento, a tentativa e até a morte (Barros, 2013). É consenso que a maioria das pessoas com ideias suicidas comunica seus pensamentos e intenções, ou seja, elas frequentemente dão sinais, e reconhecê-los pode ser o primeiro e mais importante passo. Conseguir contato pela escuta é também um recurso para minimizar a angústia e o sofrimento das pessoas com comportamento suicida (OMS, 2000).

Estima-se que $45 \%$ das vítimas por suicídio procuram um serviço de Atenção Primária à Saúde (APS) no ano de sua morte, inclusive no mesmo mês em que cometeram o suicídio (Abreu, et al 2010, Luoma, Martin \& Pearson, 2002). A APS é considerada local privilegiado para o cuidado de pessoas com comportamento suicida, por ser o primeiro recurso de atenção à saúde, em que as equipes podem estabelecer contato proximal e longitudinal, por meio do acolhimento, identificação de problemas, discussão dos casos interdisciplinarmente e o desenvolvimento de estratégias e intervenções que possam favorecer o acompanhamento dos casos. A APS se constitui como um elo entre a comunidade e a Rede de Atenção à Saúde (RAS) (OMS, 2000, OMS, 2018, Ribeiro et al 2018).

O enfermeiro como integrante das equipes da APS é rotineiramente responsável por realizar a primeira escuta de pacientes, identificar o risco de suicídio e comunicar aos outros membros da equipe multiprofissional, dando início às intervenções necessárias à pessoa com comportamento suicida. Destarte, a atuação do enfermeiro frente à pessoa com comportamento suicida inclui acolher o paciente e mantê-lo em segurança; engajar e orientar a família sobre o assunto; realizar consulta de enfermagem e articular com os demais profissionais e serviços o cuidado mais apropriado (Botega, 2015).

A formação dos enfermeiros para atuar frente a esta demanda ainda é deficiente, pois vários destes profissionais sentem-se despreparados para lidar com a temática do suicídio, com incógnitas, tabus e preconceitos em torno do tema. O paciente suicida pode ser ameaçador para quem o atende e mecanismos de defesa podem ser ativados, dificultando com que o profissional assuma uma postura acolhedora e com eficaz raciocínio clínico (Botega, 2015, Silva, et al 2017). Há necessidade de melhora do processo de formação do enfermeiro diante dos diversos contextos do suicídio seja nos cursos de graduação ou por meio de atividades de educação permanente nos serviços. Qualificar a formação possibilitaria ao enfermeiro desenvolver habilidade e competência para melhor intervir nessa situação (Silva, et al 2017, Santos, eta al 2017).

O estado de Santa Catarina faz parte da região Sul que, embora concentre $14 \%$ da população do país, possui $23 \%$ dos registros de suicídio no período compreendido de 2007 a 2016. Na região da grande Florianópolis a taxa de mortalidade por suicídio no ano de 2017 foi de 7,6/100.000 habitantes, apontando uma situação que exige atenção no que diz respeito à temática do suicídio a nível local (Brasil, 2019).

No cenário da APS de Florianópolis, a partir da implementação dos protocolos de enfermagem, o enfermeiro tem cada vez mais ampliado sua clínica e assumido um papel central no cuidado às pessoas. Dados da sala de situação do município referentes ao último trimestre de 2018 mostraram um total de 47.090 pessoas atendidas por esses profissionais, demonstrando um aumento de 6,18\% no número de atendimentos em comparação ao mesmo trimestre do ano anterior (Florianópolis, 2018). 
O protocolo de enfermagem volume 4 - Atendimento a demanda espontânea do adulto, aborda o manejo da pessoa com comportamento suicida. Além disso, os enfermeiros da APS de Florianópolis contam com a ferramenta de manejo clínico chamada PACK - Pratical Aproach to Care Kit, um guia que contempla diversas queixas em saúde, o que inclui a abordagem ao paciente com comportamento suicida e respectivas recomendações práticas conforme a base de evidências científicas do BMJ Best Practice.

Diante da relevância do tema suicídio, do papel da APS para garantir acesso às pessoas com comportamento suicida e considerando que o enfermeiro tem papel central na identificação, manejo e acompanhamento destes casos, esse estudo teve como objetivo compreender o cuidado prestado por enfermeiros da APS de Florianópolis à pessoa com comportamento suicida.

O que motivou a realização deste estudo foi minha experiência como residente de enfermagem no Programa de Residência Multiprofissional em Saúde da Família da APS de Florianópolis, quando pude observar que, por um lado, existe essa demanda referente à temática do suicido; entretanto, as discussões ainda se mostram tímidas no âmbito da enfermagem. Portanto, buscou-se conhecer como acontece esse cuidado a nível local com vistas a contribuir com as discussões sobre a qualificação do cuidado de enfermagem no que diz respeito ao cuidado à pessoa com comportamento suicida.

\section{Metodologia}

Estudo de abordagem qualitativa, do tipo descritivo realizado com enfermeiros que exercem suas atividades nos centros de saúde da APS do município de Florianópolis - SC. Segundo Minayo (2007) a abordagem qualitativa permite a formulação de novas categorias e conceitos no momento da investigação e via compreender a particularidade do objeto através de explicações situacionais e sociais que o permeiam. Para Denzin e Lincoln (2006), a pesquisa qualitativa possibilita a análise, reflexão e interpretação do universo a ser pesquisado devido, também, ao conjunto de práticas materiais. Souza (2002) situa que a abordagem qualitativa utiliza uma série de estratégias e técnicas que permitem produzir dados para estudar um fenômeno e interpretá-lo a partir da compreensão da investigação. O estudo do tipo descritivo permite ao pesquisador descrever o conhecimento sobre a realidade, as dimensões de como se apresenta e as características do contexto do objeto (Minayo, 2007).

Foram adotados como critérios de inclusão: ser enfermeiro, realizar atividades assistenciais no serviço da APS de Florianópolis e ter atendido uma pessoa com comportamento suicida. Foram excluídos aqueles que trabalham exclusivamente com atividades de coordenação/administração do serviço, enfermeiros vinculados apenas a programa de residência multiprofissional e aqueles em período de férias/atestados/licenças. Destaca-se que Florianópolis possui 49 de Centros de Saúde e 128 enfermeiros atuantes na APS.

Os enfermeiros foram convidados a participar do estudo via contato telefônico com os Centros de Saúde em que atuam, e todos que aceitaram contribuir com a pesquisa assinaram o Termo de Consentimento Livre e Esclarecido (TCLE). Os Centros de Saúde e os participantes foram escolhidos aleatoriamente, buscando contemplar enfermeiros dos diferentes distritos de saúde do município. A coleta de dados ocorreu durante o mês de novembro do ano de 2019 nos locais de trabalho em que os participantes estavam lotados conforme disponibilidade de agenda de cada profissional. A amostra foi composta por 10 enfermeiros, alocados em seis Centros de Saúde, número este obtido por meio da técnica de saturação teórica, ou seja, quando na fala dos sujeitos nenhuma nova informação foi encontrada.

Os dados foram coletados através de dois instrumentos elaborados pela pesquisadora e aplicados na mesma ocasião: um questionário autoaplicável contendo questões fechadas com o intuito de coletar informações sobre perfil sóciodemográfico dos participantes, como por exemplo: idade, nível de formação e tempo de atuação na APS de Florianópolis; e uma entrevista semiestruturada contendo questões abertas sobre o cuidado de enfermagem prestado à pessoa com comportamento suicida, tais como: "descreva o seu atendimento/cuidado ao paciente com comportamento suicida, desde o acolhimento até a liberação", "o 
que você entende por comportamento suicida?" e "que ações poderiam melhorar o seu atendimento à pessoa com comportamento suicida?", dentre outras. A entrevista foi presencial, gravada em dispositivo de mídia eletrônica, transcritas na íntegra e submetida aos entrevistados para validação antes da realização da análise. A análise dos dados ocorreu através do método de análise de conteúdo modalidade temática que envolve três etapas: pré-análise, exploração do material, tratamento e interpretações dos dados (Ferreira et al 2020). Para garantir o anonimato, os participantes foram identificados pelo dado alfa numérico E1, E2, E3 e assim por diante.

O estudo respeitou os princípios éticos constantes na resolução 466/12, que regulamenta pesquisas com seres humanos, foi submetido e aprovado pela Comissão de Acompanhamento dos Projetos de Pesquisa em Saúde (CAPPS) da Secretaria Municipal de Saúde do município de Florianópolis e pelo Comitê de ética da Universidade do Estado de Santa Catarina (UDESC) pelo número CAAE 16378719.0.0000.0118.

\section{Resultados e Discussão}

A Tabela 1 descreve características do perfil sociodemográfico dos enfermeiros da Atenção Primária à Saúde de Florianópolis que participaram do estudo. Salienta-se que $50 \%$ dos enfermeiros possuem pós graduação em atenção básica/áreas correlatas e atuam em APS por um período de 10 ou mais anos, indicando um número significativo de profissionais com experiência e conhecimento em APS.

Tabela 1 - Perfil dos Enfermeiros da Atenção Primária em Saúde de Florianópolis participantes do estudo. Florianópolis, SC, Brasil, 2019.

\begin{tabular}{|c|c|}
\hline & $(n=10)$ \\
\hline \multicolumn{2}{|l|}{ Faixa etária } \\
\hline $41-50$ anos & 4 \\
\hline 20-30 anos & 3 \\
\hline $31-40$ anos & 3 \\
\hline \multicolumn{2}{|l|}{ Nível de formação } \\
\hline Pós graduação & 7 \\
\hline Graduação & 3 \\
\hline \multicolumn{2}{|l|}{ Área da pós graduação } \\
\hline Atenção básica & 5 \\
\hline Urgência e emergência & 2 \\
\hline \multicolumn{2}{|l|}{ Tempo de formado } \\
\hline $1-5$ anos & 2 \\
\hline 5-10 anos & 3 \\
\hline $10-15$ anos & 2 \\
\hline 15-20 anos & 2 \\
\hline 20-30 anos & 1 \\
\hline \multicolumn{2}{|c|}{ Tempo de atuação como enfermeiro } \\
\hline $1-3$ anos & 2 \\
\hline 4-6 anos & 2 \\
\hline 10-12 anos & 3 \\
\hline Mais de 13 & 3 \\
\hline \multicolumn{2}{|l|}{ Vínculo trabalhista } \\
\hline Contrato temporário & 3 \\
\hline Estatutário & 7 \\
\hline \multicolumn{2}{|l|}{$\begin{array}{l}\text { Tempo de atuação na APS- } \\
\text { Florianópolis }\end{array}$} \\
\hline $1-3$ anos & 3 \\
\hline 4-6 anos & 2 \\
\hline 10-12 anos & 3 \\
\hline Mais de 13 anos & 2 \\
\hline
\end{tabular}

Fonte: Dados da pesquisa (2020). 
Da análise das entrevistas emergiram duas categorias temáticas: a categoria 1, denominada "O contexto do cuidado de enfermagem à pessoa com comportamento suicida na APS" e a categoria 2 "Limites, desafios e possibilidades ao atendimento da pessoa com comportamento suicida" as quais serão detalhadas e descritas em seguida.

A categoria $1, \mathrm{O}$ contexto do cuidado de enfermagem à pessoa com comportamento suicida na APS descreveu os aspectos do cuidado desenvolvido pelo enfermeiro à pessoa com comportamento suicida na APS. É composta por quatro subcategorias: 1.1 Concepções sobre o comportamento suicida; 1.2 Acolhimento e identificação da pessoa com comportamento suicida; 1.3 Intervenções ao comportamento suicida e 1.4 Sentimentos emergidos no cuidado à pessoa com comportamento suicida.

A categoria 2, Limites, desafios e possibilidades ao atendimento da pessoa com comportamento suicida se refere aos principais desafios e possibilidades de melhoria que envolvem o cuidado à pessoa com comportamento suicida na APS. É composta por três subcategorias: 2.1 Formação profissional dos enfermeiros da APS e educação em serviço sobre o tema; 2.2 Estruturação da Rede de Atenção para o atendimento da pessoa com comportamento suicida e 2.3 Rede social significativa.

\subsection{Categoria temática 1: O contexto do cuidado de enfermagem à pessoa com comportamento suicida na APS}

\subsubsection{Concepções sobre o comportamento suicida}

É importante destacar a concepção que os enfermeiros possuem sobre a pessoa com comportamento suicida para conhecer como estes respondem a elas, no sentido de nortear decisões. Os dados da pesquisa demonstraram que as concepções da pessoa com comportamento suicida denotaram presença de pensamentos de morte, ideação suicida e planejamento do ato associados a vivências de angústia e sofrimento pelas pessoas, conforme observamos nas falas apresentadas abaixo:

São os pacientes que têm tendência para o suicídio, que têm relatos, que têm desejo de se matar[...] ela está passando por um sofrimento e às vezes esse sofrimento para a pessoa, ela quer acabar com uma angústia e a forma dela acabar com a angústia seria a morte né, se ela morresse ela teria, ela acabaria com o sofrimento dela. (E4)

É a pessoa que está no momento de sofrimento, se vê numa situação que não tem saídas e pensa que acabar com a sua vida, digamos que é a única saída que ela enxerga para o sofrimento, para os problemas que ela vem encontrando. (E6)

[...] eu acho que só o fato de pensar, de existir essa possibilidade do suicídio, pensar em auto mutilação, ver o suicídio como a única saída, já é um comportamento suicida, antes mesmo de ter o plano estruturado assim. (E9)

As falas acima ilustram sentimentos de sofrimento e angustia, cuja morte seria a resolução. Por outro lado, ficou ausente uma reflexão de que morte se trata, o que desejaria uma pessoa matar que não a si mesma, ou seja as motivações deste sofrimento.

\subsubsection{Acesso, acolhimento e identificação da pessoa com comportamento suicida}

O acesso da população à APS em Florianópolis se dá por demanda espontânea e consultas agendadas. Os relatos dos enfermeiros apontaram que a principal forma de acesso da pessoa com comportamento suicida na APS é a demanda espontânea, e que os casos são tratados como prioridade na ordem de atendimento, conforme observamos nas falas apresentadas abaixo: 
Na maioria das vezes ele vem em demanda espontânea, vez ou outra, algum usuário que tá em atendimento comigo requisita atendimento para uma terceira pessoa, por ter identificado algum comportamento e nessas circunstâncias eu agendo, mas a maioria vem em demanda espontânea. (E10)

[...] o paciente acaba relatando lá [na recepção] que está mais depressivo...e alguns mesmo já relatam que estão com ideação suicida, as meninas já mandam para a gente e é um dos primeiros a serem chamado. (E2)

As falas demonstraram que a identificação da pessoa com comportamento suicida se dá pelo relato de querer tirar a própria vida, e que o rastreio para risco de suicido ocorre com uso de questões diretas aos pacientes que denotam mais atenção para o comportamento suicida, como por exemplo, aqueles que já convivem com algum problema de saúde mental.

Todos os enfermeiros entrevistados declararam não utilizar modelo estruturado ou padronizado de identificação e avaliação para o risco de suicídio, indicando que a avaliação do risco de suicídio se dá de maneira subjetiva, conforme observamos nas falas apresentadas abaixo:

Eu sei que tem vários modelos e até várias perguntas que podem ser feitas para avaliar se aquele paciente tem potencial para [o suicídio] naquele momento, mas não que eu coloque em prática. (E2)

Olha, modelo assim, não sigo nenhum. Assim, a partir do acolhimento mesmo, da conversa...geralmente a pessoa já chega falando assim "ah, tô com sintomas...quero tirar a minha vida." (E1)

Na consulta a pessoa vem com um sofrimento... ela vem relatando... normalmente alguma coisa que aconteceu... ela vem chorando e aí a gente questiona mesmo, se já passou pensamentos de morte, a gente questiona na consulta aquela pessoa que vem com alguma queixa psíquica né, não em toda consulta, pessoa que está bem a gente não fica questionando isso, mas aquela pessoa que já vem com um sofrimento, daí a gente acaba questionando. (E4)

A padronização de instrumentos/ferramentas para rastreio e identificação precoce da pessoa com risco de suicídio pode potencializar o trabalho dos profissionais da APS, especialmente dos enfermeiros, que atuam na linha de frente do serviço, com foco no acolhimento da demanda espontânea no que concerne à direção do cuidado a ser tomada.

\subsubsection{Intervenções ao comportamento suicida pelos enfermeiros}

A principal intervenção do enfermeiro ao comportamento suicida é a escuta. Os participantes relataram que tratam de escutar e entender as razões que possam estar relacionadas com o comportamento suicida. O vínculo também é citado como uma estratégia de cuidado, no sentido de permitir que a pessoa fale abertamente sobre o tema. Ações como estabelecimento de pacto de não suicídio, mobilização da rede de apoio, acompanhamento por meio de consultas de retorno, contatos telefônicos regulares e visitas domiciliares também foram mencionadas.

Trato de ouvir mesmo e de acordo com o que ela for me dizendo eu vou pensando em questões (E8)

A gente faz como se fosse um contrato de vida, tipo assim, um pacto [de não suicídio] com a pessoa, para reavaliar ela $(E 1)$.

A gente chama um familiar para conversar, para que possa se responsabilizar e ajudar no tratamento, não deixar a pessoa sozinha, voltar para casa sozinha... e a partir disso a gente combina assim um retorno (E1). 
Eu acabo pedindo retornos muito mais frequentes aqui na unidade... então eu vejo esse paciente muito mais, normalmente retornos diários assim até a gente conseguir estabilizar e até a gente sentir assim que esse risco está diminuindo, a gente faz esse acompanhamento bem de perto (E5).

Embora os enfermeiros refiram que não há uma avaliação de risco de suicídio sistematizada e padronizada, as falas mostram diferentes condutas e encaminhamentos realizados a depender da avaliação de cada caso. A pessoa com comportamento suicida é assistida interdisciplinarmente e o profissional com o qual o enfermeiro mais divide o cuidado é o médico de família. Ações como apoio matricial com o serviço de psicologia e psiquiatria, encaminhamento para grupos, auriculoterapia e articulação com Centro de Atenção Psicossocial e hospital psiquiátrico também foram mencionadas.

[...] em algumas situações específicas a gente precisa iniciar medicação e aí a gente faz isso em interconsulta com a médica da equipe, caso contrário a gente matricia com a psicologia. (E9)

Ninguém fica com um caso sozinho[...] eu particularmente sempre recorro ao médico de família, ele que me dá suporte nesse tipo de atendimento, para seguimento na unidade e outro setor, enfim... CAPS, matriciamento com a psiquiatria [...] ]alguns que foram para hospital, outros que foram encaminhados ao CAPS [...] (E3)

[...] o médico da equipe, psicologia... em algumas situações eu encaminho para o grupo de auriculoterapia, dependendo do perfil do paciente eu já encaminhei para outros grupos da unidade... grupo da horta, grupo de alongamento, isso tem muito a ver com a causa do sofrimento. (E10)

\subsubsection{Sentimentos emergidos no cuidado à pessoa com comportamento suicida}

Os discursos indicaram que o paciente com comportamento suicida promove nos enfermeiros sentimentos de empatia, de identificação com o sofrimento do outro, medo, angústia, insegurança no manejo e responsabilização pela vida da pessoa. As falas também mostraram um desejo de se instrumentalizarem para lidar com esses sentimentos, conforme observamos abaixo:

[...] Essa identificação pode acontecer, aí entra a relação profissional-paciente e a questão empática também, que é muito importante, mas eu também preciso ver o meu limite "essa pessoa eu não consigo atender" (E8).

É o tipo de atendimento que é bem complexo para mim, bem pesado, que me afeta emocionalmente bem mais do que os outros atendimentos. Às vezes eu me sinto angustiada por não conseguir resolver a demanda, eu me sinto impotente, incapaz [...] Queria um treinamento para não entrar em sofrimento junto. (E10)

\section{[...] Eu me sinto corresponsabilizada digamos assim pela vida dele (E1)}

Por outro lado, um participante do estudo relatou que se trata de paciente que também gera sentimentos de satisfação, quando percebem que o seu cuidado tem efeito positivo na evolução dos casos:

[...] mas tenho vários pacientes que eu acompanho e que a evolução é boa e a gente fica muito bem com isso, de ver que a pessoa está voltando para sua vida normal. Ver eles bem é muito gratificante, ver que teu trabalho dá resultado. (E9) 
A categoria temática "O Contexto do Cuidado de Enfermagem a Pessoa com Comportamento Suicida" demonstrou que esse tipo de cuidado tem acontecido na prática, e que o profissional é o próprio instrumento de cuidado, em um misto de fator humano, técnico e ético. Quanto ao fator humano os profissionais são mobilizados pelos sentimentos evocados. Quanto ao fator técnico, o acesso, acolhimento, identificação e acompanhamento são realizados baseados a partir mais da experiência na assistência do que em diretrizes clínicas, mesmo com a existência de documentos norteadores instituídos no município. Quanto ao fator ético, os profissionais se envolvem, buscam parcerias para o cuidado e se esforçam para ofertar o melhor cuidado possível.

\subsection{Categoria temática 2: Limites, desafios e possibilidades ao atendimento da pessoa com comportamento suicida na} APS

\subsubsection{Formação profissional dos enfermeiros da APS e educação em serviço}

Os excertos demonstraram que os participantes do estudo não tiveram formação específica para cuidar dessa demanda e relataram uma fragilidade para atuar com saúde mental de maneira geral. A formação referida pelos participantes do estudo foi a vivência prática acompanhando os atendimentos de outros profissionais. Relataram sentir a necessidade de treinamento para atuar, ao passo que este deveria ser voltado para a vivência prática, como oficinas e paciente simulado, além de uma formação que englobasse os aspectos subjetivos do cuidado, incluindo o cuidado do próprio profissional, conforme observamos nas falas abaixo:

A gente tem uma formação muito deficitária, pelo menos na minha graduação eu tive pouco de saúde mental, pouco de manejo de paciente mais grave. Talvez eu tenha visto algo de suicídio, mas algo muito mais teórico do que como manejar, o que é importante, o que eu não posso deixar, como que eu avalio o risco, é um risco alto? é um risco baixo? é um limite técnico que eu vejo (E6)

Na minha vida acadêmica a gente teve bem pouco contato com paciente em sofrimento psíquico, tive mais na pratica profissional, fazendo e aprendendo... ainda tenho muito o que aprender, mas é mais perdendo o medo. (E4)

A gente precisa ter um treinamento técnico, falar sobre a abordagem do paciente, como é a sequência, quais são as escalas, quais são os critérios que a gente considera de alto risco, de baixo risco, de médio risco. (E6)

[Um exemplo de treinamento que eu tive foi] em base de casos clínicos, a gente tinha grupo de discussão e roda da gente falar dos nossos sofrimentos... tanto pessoal como profissionais e isso foi muito legal. Acho que a gente precisa ser cuidada também para entender todo esse processo. (E8)

\subsubsection{Estruturação da Rede de Atenção para o atendimento da pessoa com comportamento suicida}

Os entrevistados entendem a APS como um cenário com potencial para o atendimento a pessoa com comportamento suicida, porém comentam de lacunas na rede de saúde que dificulta a resolutividade desses casos. As falas trouxeram como adversidades enfrentadas no cotidiano o acesso da pessoa com comportamento suicida ao serviço devido às mais variadas demandas que os pacientes trazem, o que implica uma agenda com tempo limitado para abordar aspectos da saúde mental, a falta de outros dispositivos de cuidado como por exemplo maior ofertas de grupos, nos próprios centros de saúde ou grupos comunitários e maior oferta de atendimento psicológico e psiquiátrico. Segundo os participantes da pesquisa, esses fatores levam a uma maior medicalização dos casos, conforme observamos na falas abaixo: 
A gente sabe que o atendimento de um paciente psiquiátrico requer tempo, e muitas vezes a agenda do enfermeiro, a quantidade de pacientes que atendemos no dia, no turno, não nos dá esse tempo para atender. (E5)

Aqui na comunidade eu não tenho praticamente nada de onde mandar essa pessoa, quando eu penso em suporte, em terapias, em outros dispositivos, outras atividades para essa pessoa... a gente se vê muito amarrado [...] a gente acaba medicalizando muito mais pois não tenho onde conseguir esse suporte, falando de rede assim. (E6)

Que tivesse uma rede mais próxima para fazer esse apoio, a psicologia todos os dias, psiquiatria todos os dias [...] (E7)

Observou-se que a estruturação da Rede de Atenção para o atendimento da pessoa com comportamento suicida ainda é uma lacuna a ser suprida para a melhoria do cuidado.

\subsubsection{Rede social significativa}

Em relação às características relacionadas à pessoa com comportamento suicida, os participantes da pesquisa citaram o contexto social e a falta de uma rede de apoio familiar e social como um aspecto que dificulta o desenvolvimento de ações de cuidado, conforme observado nas falas abaixo:

O problema são as redes, o que está por trás disso. Um caso marcante que eu tive era de um paciente que veio sozinho para Florianópolis, não tinha rede nenhuma e a gente não podia liberar ele sem rede. (E2)

Você não vai ficar lá fazendo o papel de rede de apoio, mas essa pessoa não tem ninguém. (E8)

Rede de apoio não efetiva. Estabelecer o que realmente é apoio e o que não é, às vezes a família toda está doente (E8)

Os limites trazidos pelos participantes do estudo ora se configuraram como limites, ora como possibilidades a serem trabalhadas para a melhoria do cuidado prestado à pessoa com comportamento suicida. Estes aspectos se referiram à formação da graduação e educação permanente deficitária para atuar com a temática, à dificuldade em conduzir os casos em um contexto com pouca oferta de dispositivos de cuidado para além do tratamento medicamentoso e o desafio que cada pessoa desperta quando não possui alguém para contar no momento que mais precisa, além das questões de autocuidado dos próprios profissionais para atuar frente a esta demanda.

\section{Discussão}

A compreensão dos participantes do estudo sobre o comportamento suicida vai ao encontro do que é consenso na literatura sobre a temática: o suicídio como forma de aliviar e cessar o sofrimento. Conceber que o suicídio é resposta ao sofrimento nos remete ao fato de que atenuar o sofrimento é o princípio básico dos atendimentos relacionados a essa demanda (Botega, 2015). Nesse sentido, entre o sofrimento e a morte há o que se escutar e, para isso, o exercício dessa escuta precisa ser estudada, praticada e aprimorada, contribuindo para o discernimento entre o profissional e o outro.

A maneira como a pessoa é recebida no Centro de Saúde, a atenção dispensada, a atitude no acolhimento e identificação do comportamento suicida é primordial, pois influenciará na adesão, ou não, do paciente (Sadock \& Sadock, 2007). Isso porque as características dos aspectos psicológicos da pessoa com comportamento suicida envolvem a 
ambivalência (querem mas não querem se matar), a impulsividade (que a negatividade pode gerar uma impulsão), rigidez/constrição (pensamento de tudo ou nada, ou ideia fixa a algo). Cabe ao profissional escutar e intervir sabendo destas características para que contribua no estabelecimento do vínculo e consequente continuidade do cuidado (Soares, 2015).

Neste estudo, os participantes relataram identificar a pessoa com comportamento suicida por meio do relato sobre pensamentos de morte; entretanto, nem sempre a pessoa expressa claramente seus pensamentos ou sentimentos relacionados a acabar com a vida, sendo necessário estar sensível para reconhecer os sinais e abrir um espaço para que a pessoa fale sobre o que se passa com ela durante o atendimento, o que motivou a busca pelo serviço/profissional. Isto porque o relato na recepção a outro profissional pode estar velado e no acolhimento com o enfermeiro a queixa, que antes era uma, passa a ser outra, exigindo outro tipo de abordagem e manejo clínico (Botega, 2015, Rio de Janeiro, 2016). Falar direta e abertamente sobre o suicídio é uma forma eficaz de abordar e manejar o risco de suicídio, em especial quando a pessoa chega falando sobre isso (Rio de Janeiro, 2016). Neste estudo, os enfermeiros relataram questionar sobre suicídio junto às pessoas que apresentavam alguma demanda relacionada a problema de saúde mental. Embora exista uma relação entre transtorno mental e suicídio, por vezes os pacientes com possível risco de suicídio se apresentam com queixas somáticas, por isso é importante uma escuta para captar essa singularidade inclusive nos pacientes com diagnósticos diversos (Brasil, 2006).

Embora a maioria dos enfermeiros não rastreiem rotineiramente risco de suicídio, exceto se o paciente lhe traz essa informação (Soares, 2015), é importante que uma avaliação breve seja realizada em todos os pacientes (Bertolote, Mello \& Botega, 2010). A Organização Mundial da Saúde indica o uso de instrumentos na avaliação por profissionais não-especialistas, o que inclui o profissional enfermeiro, o que auxiliaria na tomada de decisão e subsidiaria a prática profissional (Bertolote, Mello \& Botega, 2010).

Conforme a gravidade da pessoa em risco de suicídio, esta pode ser preferencialmente manejada na APS, mas isso implica na realização de estratificação de risco e a elaboração de um fluxograma que defina essas questões a partir da realidade sanitária local, planejada, pactuada e aprovada entre gestores e profissionais (Rio de Janeiro, 2016), questão esta que ainda precisa ser melhorada conforme relato dos participantes.

No que diz respeito às intervenções ao paciente com comportamento suicida, o estabelecimento de uma escuta e comunicação terapêutica é capaz de amenizar o sofrimento e contribuir para que a pessoa amplie seus recursos para lidar com a situação insuportável. O estabelecimento de um pacto de não suicídio, associado a outras medidas de apoio, é uma estratégia de prevenção ao suicídio e na maioria das vezes as pessoas respeitam essa combinação (Bertolote, Mello \& Botega, 2010). Nesse sentido, foi percebido que a maioria dos entrevistados utilizavam esta combinação de estratégias em sua prática.

Os participantes do estudo relataram solicitar a rede de apoio da pessoa com comportamento suicida para fortalecer esse cuidado e perceberam que uma rede de apoio não efetiva dificulta a condução dos casos. Uma rede de apoio social é fator de proteção para o suicídio, sendo necessário explorar possibilidades de criar/fortalecer essa rede que se encontra fragilizada ou ausente, pensando na possibilidade do apoio prático e conforto emocional (Botega, 2015).

No atendimento à pessoa com comportamento suicida pelos enfermeiros, percebeu-se que o cuidado ocorre no âmbito interdisciplinar, em rede, com compartilhamento e co-responsabilização entre os profissionais, por meio de interconsulta, apoio matricial e articulação com outros serviços da rede. Esta realidade corrobora com estudos que refletiram a atuação do enfermeiro nas demandas relacionadas ao comportamento suicida, uma vez que este deve estar preparado para identificar e avaliar o risco de suicídio, compartilhar com a equipe multiprofissional e fazer a referência e contrarreferência aos demais serviços de saúde, quando necessário; e que, diante da complexidade da temática, esse profissional não deve resolver essas demandas isoladamente, mas somar esforços e saberes. Segundo os autores, o cuidado interdisciplinar é indispensável à resolutividade dos casos (Santos et al 2017; Fukumitsu 2014). 
No que se refere aos sentimentos vivenciados pelos enfermeiros entrevistados no cuidado à pessoa com comportamento suicida, a empatia é um sentimento potencializador do cuidado, citado como recurso central do cuidado. Um contato não empático, apressado, permeado de defesas impede a avaliação clínica e o manejo terapêutico (Bertolote, Mello \& Botega, 2010). Os demais sentimentos vivenciados destacaram um campo sem garantias, impossível de prever: que o paciente pode efetivamente cometer o suicídio (Fukumitsu 2014).

No que diz respeito à formação do enfermeiro para cuidar da pessoa com comportamento suicida na APS, este estudo corrobora com outros estudos que destacaram que os enfermeiros ou não receberam formação, seja na graduação ou em serviço, ou receberam de modo insatisfatório ao passo que se sentem despreparados para atuar com essa demanda (Botega, 2015). Contudo, entende-se que se trata de um despreparo misturado, ora técnico, sem uma preparação teórico-prática, ora subjetivo, no que se refere a reconhecer que este tipo de demanda suscita sentimentos de medo e insegurança, e atualiza conflitos psíquicos. O desenvolvimento do autoconhecimento desses profissionais sobre suas emoções possibilitaria seu melhor manejo e a diminuição do estresse e ansiedade que esses pacientes provocam nos profissionais de saúde (CarmonaNavarro \& Pichardo-Martínez, 2012). Todavia, trata-se de um investimento a partir da ética do desejo: o profissional só pode realizar sua psicoterapia na medida em que desejar tratar o que lhe acontece a partir dessa demanda. Por um lado, esse investimento pode ser pessoal, o que implicaria investimento financeiro pessoal a partir de si; por outro lado a realidade sanitária pode elaborar projetos de saúde do trabalhador com espaços para falar sobre o trabalho e supervisão clínicoinstitucional para que os casos mais graves sejam compartilhados e estudados. Acredita-se que uma formação/educação em serviço a partir da realidade do trabalho seja um projeto de gestão a ser elaborado, com parcerias institucionais e métodos que consigam atender a realidade singular de cada lugar.

Embora neste estudo se trate de uma realidade local específica, os dados se aproximaram da literatura (Ferreira et al, 2018). Isto significa que se percebe um cenário diagnóstico em que o cuidado à pessoa com comportamento suicida carece de uma abordagem clínica, teórica e metodológica que dê mais robustez aos enfermeiros da APS, para que fique mais clara a função do enfermeiro nestas situações, o que se escuta e como se conduz os casos a partir do que se escuta, suscitando uma reflexão acerca da aprendizagem ofertada pelos currículos durante a formação e oferta de educação permanente pelos municípios e serviços; isto sem complexificar os paradigmas que permeiam o cuidado a pessoa com comportamento suicida, uma vez que cada paradigma diz de um lugar técnico e interventor na situação. Tais aspectos podem, por um lado, representar limites para a atuação clínica dos profissionais, mas sobretudo como uma possibilidade de melhorias e qualificação profissional e de rede.

Acerca dos aspectos relacionados à rede de saúde identificados como limites e desafios, os entrevistados demonstraram uma rede de saúde pouco estruturada para atender a demanda do suicídio. Tal fato vai ao encontro de estudo que evidenciou que os profissionais se sentem desamparados para exercer esse papel, seja por falta de tempo devido à sobrecarga do trabalho, carência de rede de apoio, poucos dispositivos de cuidado, déficit de políticas sociais e iniciativas locais de prevenção ao suicídio (Ferreira et al, 2018). Logo, o desafio passa a ser uma mobilização profissional na formulação de um projeto junto aos gestores para que os limites se tornem possibilidades e potências, para que haja a constituição de uma Rede de Atenção à Pessoa com Comportamento Suicida a ser planejada e organizada para dar conta da realidade estudada.

Outro aspecto a ser discutido diz respeito à medicalização do sofrimento da pessoa com comportamento suicida. Esse fato foi abordado a partir da falta de outros dispositivos de cuidado que poderiam trazer resultados terapêuticos, uma vez que as necessidades das pessoas não se restringem a psicofármacos, mas se relacionam com as influências do meio sociocultural, político e econômico (Botega, 2015, Eslabão et al, 2017). Estes dispositivos dizem respeito a recursos providos no território do paciente e na realidade sanitária, dispositivos que compõem a Rede de Atenção à Saúde como Núcleo Ampliado de Saúde da Família com profissionais disponíveis, bem como outros serviços como os Centros de Atenção Psicossociais e os leitos em 
hospitais gerais. É necessário também somar esforços para fortalecer políticas públicas que visem a criação de novos espaços e possibilidades de cuidado que atendam às necessidades sociais e de saúde das pessoas (Eslabão et al, 2017), considerando a complexidade da temática.

\section{Conclusão}

O estudo permitiu compreender o cuidado prestado por enfermeiros da atenção primária à saúde de Florianópolis à pessoa com comportamento suicida. Ficou explícito que estes profissionais são fundamentais nesse processo pois estão ininterruptamente fazendo o cuidado, principalmente quando identificam a pessoa em risco de suicídio, utilizam-se da escuta e do vínculo para minimizar o sofrimento, mobilizam a rede e articulam com outros profissionais. Acredita-se que um projeto que busque dialogar a respeito de instrumentos que permitam avaliar o risco de suicídio, que sirva para qualificar e subsidiar a prática profissional e que norteie as intervenções, possa ser um caminho a ser refletido e implementado, além das ferramentas já existentes no município. Também se considera importante a formulação de um projeto que vise a educação permanente dos profissionais com parcerias interinstitucionais para oportunizar momentos de treinamento que englobem não somente os aspectos técnicos-práticos, mas também os aspectos subjetivos do cuidado, possibilitando um melhor exercício da escuta e melhor manejo dos sentimentos que emergem ao cuidar do paciente com comportamento suicida, cuidando também do profissional cuidador.

Esta pesquisa salienta a necessidade de um projeto de Rede de Atenção à Pessoa com Comportamento Suicida tendo em vista os dados epidemiológicos e a complexidade intersetorial que envolve o tema para que os profissionais, gestores e população possam juntos pactuar ações a serem realizadas e avaliadas em conjunto, sugere-se que os planejamentos de melhoria da rede de saúde possam contemplar as demandas relacionadas à pessoa com comportamento suicida e que fluxogramas possam ser desenvolvidos visando a construção de uma linha de cuidado voltado para a pessoa em risco de suicídio, uma vez que a resolutividade dos casos está relacionado ao cuidado interdisciplinar e intersetorial. Para trabalhos futuros sugerimos ampliar o escopo da pesquisa para outros profissionais além da enfermagem, na medida que a equipe também atua em situações de risco de suicídio e investigar os efeitos da qualidade do cuidado profissional prestado à população vulnerável a partir de educação permanente e pactuação de fluxos e manejo na Rede de Saúde.

\section{Referências}

Abreu, K. P., Lima, M. A. D., Kohlrausch, E. \& Soares, J. F. (2010). Comportamento suicida: fatores de risco e intervenções preventivas. Revista Eletrônica de Enfermagem, 12(1),195-200. 10.5216/ree.v12i1.9537

Almeida, L. N., Gonçalves, A. F., Silva, J. \& Rocha, R. A. M. (2015). O suicídio no brasil: um desafio às ciências sociais. Revista Brasileira de Estudos Latino-Americanos, 5(3),510-591. https://rebela.emnuvens.com.br/pc/article/view/252/633

Barros, M. N. S. (2013). Introdução In: Conselho Federal de Psicologia. O suicídio e os desafios para a psicologia. Conselho regional de psicologia.

Bertolote, J. M., Mello, S. C. D. \& Botega N. J. (2010). Detecção do risco de suicídio nos serviços de emergência psiquiátrica. Revista Brasileira de Psiquiatria, 32(Suppl 2),87-95. 10.1590/S1516-44462010000600005

Botega, N. J. (2015). Crise suicida: avaliação e manejo. Artmed.

Brasil, Ministério da Saúde (2006). Prevenção do Suicídio. Manual dirigido a profissionais das equipes de saúde mental. Universidade Estadual de Campinas, Organização Pan-Americana da Saúde. https://www.cvv.org.br/wp-content/uploads/2017/05/manual_prevencao_suicidio_profissionais_saude.pdf

Brasil, Ministério da saúde, Secretaria de Vigilância em Saúde (2019). Suicídio: tentativas e óbitos por intoxicação exógena no Brasil, 2007 a 2016. 50(15). https://portalarquivos2.saude.gov.br/images/pdf/2019/julho/17/2019-014-Publicacao-02-07.pdf

Carmona-Navarro, M. C. \& Pichardo-Martínez, M. C. (2012). Atitudes do profissional de enfermagem em relação ao comportamento suicida: influência da inteligência emocional. Revista Latino-Am Enfermagem, 20(6),1161-1168. 10.1590/S0104-11692012000600019.

Denzin, N. K, Lincoln, Y. S. (2006). O planejamento da pesquisa qualitativa-teorias e abordagens. Artmed 
Research, Society and Development, v. 10, n. 11, e501101120002, 2021

(CC BY 4.0) | ISSN 2525-3409 | DOI: http://dx.doi.org/10.33448/rsd-v10i11.20002

Eslabão, A. D., Coimbra, V. C. C., Kantorski, L. P., et al. (2017). Rede de cuidado em saúde mental: visão dos coordenadores da estratégia saúde da família. Revista Gaúcha de Enfermagem, 38(1), e60973. 10.1590/1983-1447.2017.01.60973

Ferreira, A. M. D., Oliveira, J. L. C., Souza, V. S., et al (2020). Roteiro adaptado de análise de conteúdo - modalidade temática: relato de experiência. Journal Nursing Health,10(1), e20101001. 10.15210/JONAH.V10I1.14534

Ferreira M. L., Vargas M. A. O., Rodrigues J., Trentin D., Brehmer L. C. F. \& Lino M. M. (2018). Comportamento suicida e atenção primária à saúde. Enfermagem em Foco, 9(4),50-54. 10.21675/2357-707X.2018.v9.n4.1803

Fukumitsu, K. O. (2014). O psicoterapeuta diante do comportamento suicida. Psicologia USP, 25(3),270-275. 10.1590/0103-6564D20140001

Souza, A. M. A. (2002). Problemas de investigación y deseños en estudios cualitativos. In: Mercado J. F., Gastaldo, D., Calderón, C. (orgs.). Paradigmas y deseños de la investigación cualitativa en salud. Guadalajara: Universidade de Guadalajara.

Luoma, J. B., Martin, C. E. \& Pearson, J. L. (2002). Contact with mental health and primary care providers before suicide: a review of the evidence. American Journal Psychiatry, 159(6),909-916. 10.1176/appi.ajp.159.6.909

Minayo, M. C.S. (2007). O desafio do conhecimento. HUCITEC.

Organização Mundial da Saúde (2000). Prevenção do suicídio: um manual para profissionais da saúde em atenção primária: https://www.who.int/mental_health/prevention/suicide/en/suicideprev_phc_port.pdf

Organização Mundial da Saúde, Organização Pan Americana de Saúde (2018). Folha informativa - suicídio: https://www.paho.org/bra/index.php?o ption=com_content \&view=article $\&$ id $=5671$ :folha-informativa-suicidio $\&$ Itemid $=839$

Prefeitura da cidade do Rio de Janeiro, Secretaria Municipal de Saúde, Superintendência de Atenção Primária (2016). Avaliação do Risco de Suicídio e sua Prevenção https://subpav.org/download/prot/Guia_Suicidio.pdf

Prefeitura Municipal de Florianópolis, Gerência de Inteligência e Informação, Assessoria de Planejamento Estratégico e a Diretoria de Atenção em Saúde. Sala de situação. http://www.pmf.sc.gov.br/entidades/saude/index.php?cms=salas+de+situacao\&menu=4\&submenuid=152

Ribeiro, N. M., Castro, S. D. S., Scatena, L.M. \& Haas, V.J. (2018). Análise da tendência temporal do suicídio e de sistemas de informações em saúde em relação às tentativas de suicídio. Texto Contexto Enfermagem, 27(2), e2110016. 10.1590/0104-070720180002110016

Sadock, B. G., Sadock, V. A. (2007). Compêndio de psiquiatria: ciência do comportamento e psiquiatria clínica. (9a ed.), Artmed

Santos, R. S., Albuquerque, M.C.S., Brêda, M. Z., et al. (2017). A atuação do enfermeiro com a pessoa em situação de suicídio: análise reflexiva. Revista Enfermagem UFPE,11(2),742-748. 10.5205/1981-8963-v11i2a11995p742-748-2017

Silva, N. K. N. D., Carvalho C. M. S. D., Magalhães J. M., et al. (2017). Ações do enfermeiro na atenção básica para prevenção do suicídio. SMAD, Revista Eletrônica Saúde Mental Álcool Drogas, 13(2):71-77. 10.11606/issn.1806-6976.v13i2p71-77

Soares M. H. (2015). Prevenção do suicídio. In: Soares M.H., organizador. Saúde mental: novas perspectivas. Yendis. 